\title{
Does Gender Equality Base Selection, Pose Serious Challenge for Researchers? A Review Based on Earlier Studies
}

\author{
Ghulam Nabi ${ }^{1} \&$ Song Wei ${ }^{1}$ \\ ${ }^{1}$ School of Public Affairs, University of Science and Technology of China, China \\ Correspondence: Ghulam Nabi, School of Public Affairs, University of Science and Technology of China, No. \\ 96, Jinzhair Road, Hefei, Anhui Province, Peoples Republic of China. E-mail: ghulam@mail.ustc.edu.cn
}

Received: February 9, 2015

doi:10.5539/ijbm.v10n5p222
Accepted: March 9, 2015

Online Published: April 20, 2015

URL: http://dx.doi.org/10.5539/ijbm.v10n5p222

\begin{abstract}
The basic purpose of this study is to analyze the various researches conducted by different researchers with multiple perspectives to identify their contribution in analyzing gender equality from the recruitment and selection perspective of the new employees. This study has classified these researchers under the various categories to understand them with proper objectivity, so that some valuable suggestion can be drawn, that may be helpful for further studies to reach the best possible solution of this most serious aspect of the gender equality. It has been concluded that a comprehensive study is needed to address the broader area of recruitment and selection, preferably in the government controlled institutions, because of its impact on macro level across the decision making levels in the country. This study is significant as it summarizes the studies under the various categories that not only are helpful for further analysis but also serve as guidelines to understand the new aspects which enable us to design a comprehensive study for finding an effective solution to this global concerning phenomenon.
\end{abstract}

Keywords: recruitment, selection, gender equality, politics, transparency, stereotypes, male dominancy

\section{Introduction}

From the human resource management perspective, the first most crucial and difficult human resource management strategy for achieving organizational goals is recruitment and selection strategies as the outcome of recruitment and selection strategy can be very productive for the organization if they selected right person in terms of appropriate skills mix and also very non productive if wrong one was selected and this can lead failure of the organizations (Compton, 2009; Canton, 2004). Starting with this point, that right selection is most crucial for the survival of the organizations but this is talking half of the story especially when concerning about the employees selection because this only focuses on the right person in terms of knowledge, skills and abilities that are required by an origination keeping on view the resource based concerns of (Phillips, 1995) that pleads that the gender equality is being dealt according to the benefit point of view that an organizations may get after hiring an employee, whiles as the other part of the story is female selection which in research is referred as gender selection for the organizations and is equally significant for the organization as it is the only factor of social diversity of the overall workforce diversity a crucial element for the productivity of an organization because diversity due to gender on the top positions brings various advantages in the way of making decisions in a specific situation as both male and female way of assessment to handle a specific situation are different that is beneficial for the organization. Weidekamm and Willer (2012) and Liu (2013) has elaborated in his study regarding the women in top, that women managers have full capacity to handle the issue or concerns of stakeholders arising due to the changing environment acceptable to all, however he stressed the need that they need institutional or systematic support to advance in their career.

Today in the developed world of literature now the pro and cons of the both sides of recruitment and selection are very evident and clear that both male and female generally known as gender equality is a key to be successful in terms of quality and ethically because this satisfies both justice and resource based arguments (Phillps, 1995; Tigen, 2000). The issue is that besides of all these findings that the gender equality is significant for the organizations from different perspective for an organization in any sizes and types but even then there is still great gender gap across the world specially in the top governmental management of the advanced countries (Nabi \& Song, 2014) in spite of all that there had been major international conventions to foster and maintain 
gender equality across the all levels of decision making various forums have been arranged and organized at both national and international level specially CEDAW) 1979 and UN Beijing Platform 1995 are most important to mention. Besides of this we have noted that there is lack of at least a reasonable amount of consensus of what actually causes the gender inequality in the recruitment and selection phase of new employees. This is the main focus of this review papers which analyzes some important researches particularly focusing the gender selection from the recruitment and selection perspective and will discuss different aspect that has been covered by the research studies, so that to understand some new aspects that may add the existing body of knowledge in this field as we believe that there is no end point of understanding the reality from the various angles and perspectives.

\section{Theoretical Framework}

Before we start analyzing the earlier studies, it is necessary to elaborate the way this study addresses the review process of the earlier studies about the gender equality. It is pertinent to understand the process of the recruitment and selection process to understand where the researchers have focused more regarding the researching the factor of gender equality. There are two phases to make new selection of employees needed by the organizations, the first one is to generate a large pool of applicants and then make the best selection out of them (Barbar, 1998). Recruitment is equally important to study because effectiveness of the selection directly depends on the how large and qualitative is the pool of applications. Many human resource management researchers have argued that the survival and success of an organization lies on how effective the practices of recruitment and selection are taking place (Ofori \& Aryeetey, 2011). Actually the process of making a new selection starts far earlier then the starting point of traditional selection mechanism which according to Figure 1 is showing, it actually starts from the point of those particular needs which organization is seeking to have to perform the routine activities and then these are being translated into the job description, job specification and job evaluation. Here is the starting point when the Figure 1 is being followed more or less same in all organizations regardless of public or private sector to select the right person on right job.

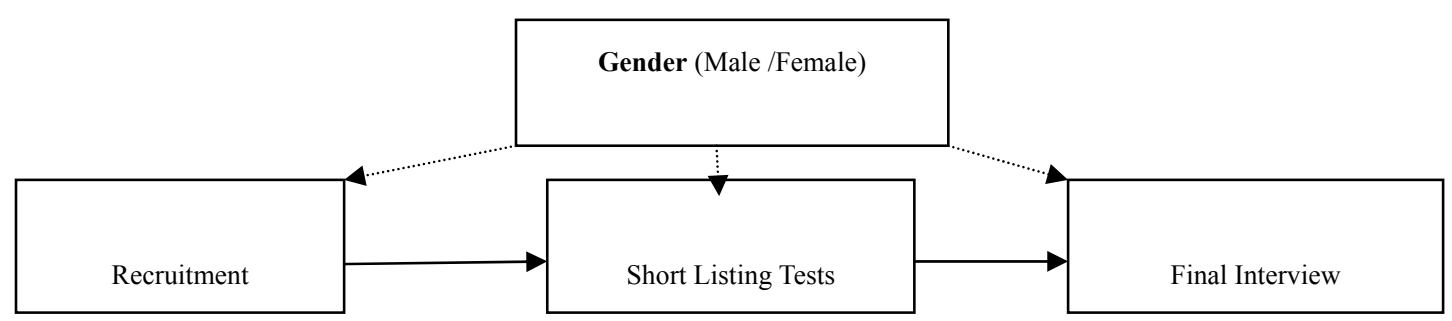

Figure 1. The process of selection in organizations

Therefore, this research will have focus on this visible part of the recruitment and selection of those studies which will have studied gender equality directly or indirectly from the recruitment and selection perspective of getting a job in an organization. Keeping in view the objectivity of the analysis with reference to the figure 1 which is highlighting that gender selection at all the three stages in the overall process of recruitment and selection of a new employees, this research study adopts a different strategy as compare to the earlier reviews to make a phase wise analysis in the context of recruitment and selection methodology, so that we may understand the understudy phenomena of gender equality in the light of earlier studies properly. It is pertinent to stress here that those studies which have made their research keeping their focus only on one part of the whole recruitment and selection process will have definitely limitations of being generalized of their findings because the recruitment and selection are being considered interrelated and interdependent which influence to each other (Rynes \& Barber, 1990) and this seems logical and rational as well. If the recruitment process will not be effective to bring enough pool or applications the right selection becomes very difficult for any specific job (Carless, 2007) and this when concerned about brining gender equality in an organizational setup or maintaining the workforce diversity become more crucial to understand the reality properly.

\section{Study of Earlier Literature}

\subsection{Transparency Issue \& Specific Networks Issue}

Schnackenberg et al. (2014) have defined that the transparency with reference to the field of management consists of the three levels the disclosure of information, its accuracy and clarity. Researchers have raised 
various concerns over the transparency of the selection procedures that according to (Brink et al, 2006) is very critical. Some researchers argued that women candidates qualify more in open competition as compare to male candidates which (Van Balen, 2001) has found that this is because of the lack of the transparency in selection procedures. Researchers have been arguing on the basis of their research findings that transparency has remained a top issue in the gender selection for bringing gender equality, especially when the authorities practices such selection evaluation process which is confidential by nature because in an open selection evaluation system the females have more chances to be selected (Husu, 2000; Ziegler, 2001). Brink et al. (2010) has argued in his research that the lack of transparency in the selection can cause more favour to a specific candidate because in flexible criteria's in the selection evaluation, the panel members may change their opinion that can be due to power game as well. Dory (2010) has mentioned that many issues that are causing due to ambiguities are causing due to lack of clarity in the standardized procedures, which makes those who are in the power strong to make involvement that may affect the process. Researchers generally argue that in open competition the women perform better but due to the lack of transparency in selection procedures it has influenced the gender selection (Van Balen, 2001; Broun's 2000). Husu (2000) has found in his study that in the open competition the women were selected twice as compare to the males. Researchers generally argue that in open competition the women perform better but due to the lack of transparency in selection procedures it has influenced the gender selection (Van Balen, 2001; Broun's, 2000).

Gender inequality had remained all time issue especially for the top management positions for women even among the developed countries as well and in Scandinavian countries the gender equality policy has remained central policy but still there is male dominancy in the public sector institutions which (Tigen, 2002) has described as paradoxical phenomena. Actually there are multiple reasons of not allowing the women in appointments and according to the (Van Balen, 2001) who has found that one of the issue is lack of the transparency in making the female selection and another reason.

Researchers have identified that there are specific networks in the organizations that play a crucial role in career opportunities and it is difficult for the women to make an access with these networks (Van Balen, 2001; Harris, 2002). Mcguire (2002) has explained that network members were least concerned about their investment in males, rather they were more interested in to invest in the males because of the males as powerful as compare to the females. Mcguire (2002) have analyzed in this study of the formal sector in which he found regarding the informal networks that apart from whether it is the white or black female in the organization, regardless of their strength by having contacts with the powerful employees, the white men are always having more cooperation from these informal networks.

Górecki and Kukołowicz (2014) has found in a study on the women legislations members who were selected on quota systems basis for women that although their number increased but on other hand their performance also decreased regardless of their past relevant experience as legislator. Researchers have been arguing that the organizations and the authorities have been defining and giving more weight to those job related activities, tasks and roles which disfavor the female and favour male applicants (Ely, 2000). Various studies have mentioned that people use discourse to identify themselves without prejudices and believer of equality while as they show the gender prejudice (Kusterer, 2014). Chi and Li (2014) have found in their study on gender that since 1980s the gender gap in the mainland of china is being increasing and this increase is more for the females by $8 \%$ as compare to the male in the employment.

From the perspective of the above mentioned studies by the different renowned researchers regarding the transparency and different networks that does exist in the organizational systems, it is evident that these two are one of a prime issue that is hampering the issue of gender equality in the organizational employment structure. It is relevant to argue here that the main issue of the transparency which the researchers have repeatedly found is due to the ambiguities in the selection procedures and the way this mechanism is functioning in which the women is being deprived of making its full participation. This is further been deteriorated due to the existence of a dominant networks in different organizations that are causing the issue of gender inequalities in the organizations which ultimately become the main threat for the workforce and social diversity of the organization. The dominant factor of these phenomena is that this transparency factor has penetrated across the organizations from top to the bottom. What we have analyzed from these studies is what (Chi \& $\mathrm{Li}, 2014$ ) has found in this study in the context of china, that the main issue in the way of a larger gap between the male and female employees in an organizations is happening due to having a different selection systems, which he termed as nonrandom selection methods. Here we have envisaged a problem which needs a specific attention is focusing the overall selection methods transparency in the context of relevancy of the selection panel/board members' and their basic intention to adopt the merit by avoiding taking external environmental pressures, especially from the 
political environment (Nabi et al., 2014). From the other points of viewed studiesare lacking to analyze how the process of organizational key authorities basic intentions have been evaluated while making studies on the selection methods transparency regarding gender balanced selectionbecause without their support the ambiguities cannot be a problem for the making a female possible to be appointed because these are the people who manage the overall affairs of the organization and can take notice of anything that may cause the issue of transparency. So we stress here that the issue of selection of females methodological problems and specific networks aremainly causing due to the silence of the key organizational key authorities, which proves that there is a link between the organizational key authorities silence and persistence of ambiguities that cause the issue of transparency that needed to be tested in a broader spectrum.

\subsection{Issue of Male Dominancy and Female Stereotypes}

Khurana (2002) has mentioned in his study that it is difficult for a women to be selected if the panel or committee is being male dominated. Brink et al. (2006) has elaborated that the gender discrimination can be avoided if organizations would adopt open selection (advertising the post in the journals or newspapers) as compare to the closed or semi open selection procedures. Brink et al. (2006) has found that women can have more probability to be appointed if the selection committee consists of a significant number of women members. According to the (Lews, 2002) is the male dominancy in the selection committees which influence the female selection. Even in the academic institutions (Brink et al., 2011) has argued that although the academic excellence is considered neutral, while as considering the gender about the merit but in Netherland based study he found that this doesn't hold true and actually the prevailing practices in academic practices in academic excellence are supportive for the male dominancy. Researchers have argued that it has been found during the analysis that, every step of recruitment and selection process is being gendered which starts from writing the profile for a job according to the male applicant in mind and this is also influenced by the similarity to me selection philosophy which is normally male dominated (Ben Chop \& Broun's, 2003; Fogelberg et al., 1999). Gender inequality had remained all time issue especially for the top management positions for women even among the developed countries as well and in Scandinavian countries the gender equality policy has remained central policy but still there is male dominancy in the public sector institutions which (Tigen, 2002) has described as paradoxical phenomena. This if we see from the perspective of (Lam et al., 2012) who have identified in their studies regarding CEOs in the private owned firms and found that this ratio is just $4.4 \%$ which is rising in the private sector gradually that is because of competitive forces that discourage the discriminatory practices which highlights the concerns of male dominancy being a factor of causing female discrimination.

Gender bias is not only due to male dominancy but also the females have more stereotypical perception towards male applicants and (Cole et al., 2004) found in his study on the recruiter evaluation process of the candidates that during the selection process the male recruiter views gender qualification \& experiences same, while as female recruiter showed tilt towards male applicants. Ben chop and Broun's (2003) has noted that the selection board has not selected women because of the similar to me reason in spite of all this that they had same qualification and were on merit too. Steipreis et al. (1999) has reported that women and men both selected the male candidate by ignoring the fact that both had equal and same level of qualification, which implies females have gender bias towards male as well. Krymkowski \& Mintz (2008) has found that the stereotypes associated with the nature and type of the job does have an effect on the women aspiration to make a job for her. Syed (2009) has found in a study based on Turkey and Pakistan, that shariah and secularism are causing major hurdle in promotion gender equality agendas in these countries. It may be has an impact on the female stereotypes that has caused gender bias of male dominancy because it has been argued in a selection of employee study that females have more stereotypical perception towards male applicants. Huddy and Terkildsen (1993) have identified that generally for the big offices on national level to become an executive the "masculine" characteristic of the stereotypes have become one of a main hurdle in the way of gender based selection. It has been in a study that women are showing a reluctant behavior in pursuing their advancement of career and they prefer a work that maintains work life balance (Doherty, 2006).

The controversy regarding the gender equality in the context of selection mechanism had remained a long standing issue from the centuries. Today in the modern civilization across the globe the researchers have maintained a particular focus on why and how the gender inequalities are being taking place in the organizations but still there seems no consensus of what actually is causing the imbalance between the male and female existence in the employment structure of an organization. However, most of the researchers have found that whether directly or indirectly male seems dominant in all levels of the different organizational setups and this we can noted it generally as well. But regarding to the male dominancy as a factor of creating hurdle for the females to get the jobs in the organizational set up is what seems more serious issue because it has been found that almost 
and always the selection panel or boards are being dominated by the males and may be due to the similar to me as factor is influencing negatively to the female selection, which we understand that there is a study needed that may have a particular focus on the other side as well, which is if the panel is dominated by the male then what about the applicants gender proportion that are appearing in the different selection tests and interviews. It has been noted that earlier researchers have been focusing one aspect by neglecting that such study may not have proper validity because of the concern that if there are only male or they are in large majority, then how can be findings based on such studies be generalized. May studies have connoted that if the selection panels or boards comprise proportionate female representation, this will solve the problem of gender equality based selection, which (Tate \& Yang, 2012) have analyzed in their study in a Chinese context of the firms in which they found that the selection of females in the top management position foster more female oriented environment. This we agree with partially because there are researchers who have identified that female stereotypes are another problem that are one of a factor that is causing the hurdles in the way of equality based gender selection. The most important aspect of this logic is that by brining female equal or proportionate representation in the selection panels or boards, will this solve the issue because one aspect is that even if there are females in the selection panel, the situation doesn't change, females selection will still remain the problem according to the various findings. This has been proved true in a study which has macro level focus of identifying the male and female representation in those cabinets or top federal /central government structure that was headed by the female as prime minister or chief executive and it was found that although regardless of gender policies, the male were dominant by almost 80 percent which is alarming for the researches and authorities as well to streamline their researches more objectively (Nabi \& Song, 2014).

\subsection{Political Issue and Gender Capability}

Syed et al. (2009) had suggested that the important factor of gender equality is their historic culture, socio political and economic setup, Weidekamm and Willer (2012) argued that diversity due to gender on the top positions brings various advantages in the way of making decisions in a specific situation because both male and female way of assessment to handle a specific situation is different that leads in the benefit of organization but the gender equality has always become an issue of how to measure it because it has always remained a political issue based on the priorities of the decision makers in the organizations (Moser, 2007). The researchers have claimed that the measurement of the gender equality is a technical and political issue, especially when it comes about the measurements of the gender equality progress, which always depends on the priorities of the decision makers (Moser, 2007). There is no doubt about the women capability even in the politics speaks but they are not doing enough for the other women politicians as highlighted by (Ferreira, 2014) that female once become elected have more ability to be re-elected as compare to their counterpart male candidate and this has not any positive impact over the other females to win in the election. Earlier researchers have found that women is the only component of the social diversity and in the light of Eastern Europe, North America and Scandinavia countries studies he has found that the under representation of women's has caused a great positive impact on the public policies and an issue for the democratic setup of these governments (Norris, 2006). Górecki \& Kukołowicz (2014) have found that the mandatory quotas for bringing more women in parliament have shown a considerable increase of the women but at the same time this has shown a fast down fall in their performance regardless of their past background of experiences. Schofield and Goodwin (2005) have found that in order to make a gender based policy the major issue for such policy making is actually the multi level structure in the process of formulating a public policy for the gender equality.

In many countries are hiring top position or executive are being selected with the approval by the top politicians and rest are being selected through organizational internal prevailing mechanism (Krause, 2006). The struggle of appointing officials in the public sector organizations between the president and other ministers depends on the pressure from their supporters as President has more pressure as compare to the other ministers to appoint near relatives or supporters in the state owned institutions even they try to do this with the lower level jobs as well (Schneider, 1992). There is no doubt about the women capability even in the politics speaks but they are not doing enough for the other women politicians as highlighted by (Ferreira, 2014) that female once become elected have more ability to be re-elected as compare to their counterpart male candidate and this has not any positive impact over the other females to win in the election. Kusterer (2014) has made a study on a women empowerment project to unfold the discourse which is concerned about women on top positions of corporate sector and he argued that there was not much progress on brining equality on top positions which may be due to the change in government.

In various researches it has been found that in order to make an effective and good corporate decision making the women have proved to be adopting more care and caution as compare to their male colleagues (Huang \& Kisgen, 
2013; Levi et al., 2014). Tong (2003) has identified in testing of situational theory in China that there is no impact of women domestic burdens on their political culture and participation in politics, which we too argue with reference to keeping in mind the top women executive in power. Marshall and Ramsey (1999) have concluded in their study on the use of gender in resolving the conflicts that the most significant indicator of seeking peaceful solutions by avoiding use of forces is to enhance the gender empowerment effectively in the country because it has been identified in the earlier studies of those who are proponent of feminist theory in the context of international disputes that by empowering gender can better solve the international conflicts because it has been found that women are less supportive to use the force in the foreign policy as tool to solve the disputes (Bendyna et al., 1996). Vigoda (2000) has identified that organizational politics has affecting negatively the employees reaction and has found that in the public sector organizations the employee prefer silence by showing negligent behavior if they feel politics around them, as they don't want to quite the job. Women politicians have capability to perform better as mentioned by (Ferreira, 2014) who suggested that from the political skill wise the female victors have superiority over their similar male colleagues who won the election. Jacobs et al. (2013) have found that the social conditions which have yet being researched are causing such a political climate that either favors or disfavors the women in their election for these offices. Norris (2006) has stressed on the basis of earlier researches on gender in the North America, Eastern Europe and Scandinavia countries that there are great consequences and impact on the agendas related to those of public policies and overall democratic setup due to keeping women under representation in the legislation because after all the legislators should be similar of those whom they are going to serve. Liu (2013) has elaborated in his study regarding the women in top, that women managers have full capacity to handle the issue or concerns of stakeholders arising due to the changing environment acceptable to all, however he stressed the need that they need institutional or systematic support to advance in their career.

From the political aspect the gender equality has always remained one of a miserable field that needed the political attention and will to resolve this issue because it is the politics that is running the overall affairs of the country. No one can deny the fact that if the rulers of any country intend to solve any problem, they can do it through strict legislation formulation and their implementation but this is what is happening on the country level but also on the international level, that politicians at all levels are showing that they are serious for the gender equality but fact is that by practically they are showing raising their popularity and female attention to seek the votes. Through researchers have identified that this issue has always been the matter of the priority of the politicians due to which it has become one of a paralyzing issue at all levels of the decision making within and outside the government. In the organizational setups these politicians are making their own appointments through different sources on the top and then penetrating the overall organizational affairs within those political appointments which have been identified in earlier studies as well (Nabi et al., 2014). The problem with the existence of the politics within the organizations leaves an impact on the overall reaction of the employees because (Vigoda, 2000) has found that in such cases mostly the employees maintain silence because of the fear of losing the job and bureaucrats avoid confrontation with the politicians of the same fear of damaging confrontation (Huber \& McCarty, 2004). Here researches are lacing to have a focus on looking that how the female as politicians, bureaucrats and employees perceive the feasibility of solving the gender equality issue through an effective gender policy which seems a very uphill task. Therefore, it is pertinent to involve the female at all employment level to find an effective solution to formulate such gender equality recruitment and selection policy that may bring improvement in this scenario which (Schofield, 2005) have concluded that there is a great care needed to understand the gender politics (which is based on dynamics of the gender deep routed in the social practices and relations involved in the process of making public policy regarding the gender equality.

Researchers have identified today the female are fully capable of performing the job in all fields as like to their male partners and in some cases the female involvement can make the decision making very productive for the all stakeholders. The interesting phenomenon is that female if involved in the international disputes decision making can have better and peaceful results. Even in politics if they will be involved properly they can have better results as compare to their male counterparts and by their participation in the top governmental and institutional matter women can play a crucial role because according to the (Levy \& Loken, 2015) who have identified that because of the female approach in setting the organizational matters more comprehensively with better results as compare to the male counterparts and being depending on other organizational members, which we believe supports to build an effective team work as compare to the male employees. Precisely commenting it seems that researches have been adopting a piece meal approach to identify that why in-spite of all this that women are capable and even more productive than male are not being able to be appointed in the organizational jobs, which this review highlights that there is a research needed to focus on this phenomena on a macro scale with a specific attention on the government public sector and the gender policies of the independent national and 
international organizations because the change floats from the government which is being guided and sometimes forced by these independent organizations to make an effective gender policy for gender equality.

\subsection{Issues of Traditional Barrier}

Brink et al. (2006) has found that women can have more probability to be appointed if the selection committee consists of a significant number of women members. Linghag (2009) and Renemark (2007) have reported that in many Swedish researches it has been found that the traditional gender norm have been kept preserved and according to Kusterer (2014) if you want to maintain gender equality on the top then this traditional phenomena must be checked to realize the gender equality objective. Gneezy et al. (2008) has observed in Indian context that females are not participating in risky and competitive behaviors as like male which according to (Górecki \& Kukołowicz, 2014) is untrue and he found that women do take part equally in all sorts of risky and competitive behaviors and it has nothing to do with the inherent genetics. Ben chop and Broun's (2003) has noted that the selection board has not selected women because of the similar to me reason in spite of all this that they had same qualification and were on merit too. Various studies have mentioned that people use discourse to identify themselves without prejudices and believer of equality while as they show the gender prejudice (Kusterer, 2014). Ely and Meyerson (2000) have identified that mostly only those females have made their job that were white and with the help of education and training the females can occupy those positions in the field of business and professional that were traditionally held by the male. (Marshall \& Ramsey, 1999) have stressed that by empowering the female there will be positive effect on the policies and the way actions are being taking place, however if we empower a single women in a dominant environment, that will not bring any change in the context of using force but a real change will occurs when the gender empowerment takes place in groups. CAWP (2010) has reported in a study that generally the women avoid making their affiliation with any political organization and even they don't make contact with their elected representative, even they prefer not to work in the political offices, although there are studies who argue that the presence of women candidates in the politics encourages the other females by giving the notion that these offices doesn't belong to the males only (Dolan (2006a). Brookman (2012) has identified that woman presence in an office of the United States seems damaging for the other females along with other factors that cause problems for women working in various offices and concluded that female presence are not helping other females to get selected.

This is one of another factor that hampers the gender equality which if we analyze it from the context of overall social behavior that are prevailing in our society that makes up our culture and has a direct impact on their way of their different behaviors which either support a new system or become the problem for it. From the context of the traditional norms, the most serious one is the way different organizational stakeholders perceive the strength and weakness of male and female which becomes the hurdle for the female selection, that is why it has been argued that in order to bring workforce diversity on the top organizational employment structure, the traditional barriers must be overcome. The issue of these researches is that the definition of these traditional barriers and then analyzing them across the geographical boundaries that has different culture and governmental policies to enhance their validity of generalization. Another factor is the way these women and males prejudices which we understand are becoming base for all other issues from male dominancy and women stereotypes. The researches needs to be targeted to how to change the mindset of the females about their interest to apply for the jobs that are dominated traditionally by the male employees because (Krymkowski \& Mintz, 2008) has identified the same, that women can be brought more in organization if they will be encouraged to go for these nontraditional jobs. Analyzing the reality of gender inequality from the context of policy making focusing on recruitment and selection that promotes gender based selection, needs to be analyzed more thoroughly by covering maximum possible factors that may be involved in policy making and its implementation causing hurdles at different stages of the overall selection process.

\section{Conclusion}

It has been observed that the most difficult job for these researchers was how to address all the extraneous factors that may apparently be involved in the gender based selection or may not be seen on the first look to analyze them and their association more precisely. Secondly, while analyzing the previous researchers there is not any vivid conclusions that could be associated as the main hurdle for the selection of equal number of male and female. On the other hand it is also been noted that the population area of the finding the causes that create hurdle for the equality of gender does have an impact on the findings of the study because a study that is being in the context of public sector shows different conclusions even within the government controlled public sector, the level of management and institutional setup also matters. Furthermore, it is also been concluded that most of the studies focusing on the gender equality and women empowerment does have a problem of lacking intuitional support both theoretical and practical as well. Even when we see the international conventions under the 
umbrella of United Nations, this problem has remain same or have been increased with a negligible margin which make the issue more sever and complicated because this directly raises the question of their intention to control this genuine problem. Studies with the notion of male dominancy as a factor of creating hurdle for the females to get the jobs in the organizational set up is what seems more serious issue because it has been found that almost and always the selection panel or boards are being dominated by the males and may be due to the similar to me as factor is influencing negatively to the female selection, which we understand that there is a study needed that may have a particular focus on the other side as well, which is if the panel is dominated by the male then what about the applicants gender proportion that are appearing in the different selection tests and interviews. It has been noted that earlier researchers have been focusing one aspect by neglecting that such study may not have proper validity because of the concern that if there are only male or they are in large majority, then how can be findings based on such studies be generalized.

Finally, we have reached on the point to say, that a research that starts to study the complete recruitment and selection process at large level by involving all the factors that may have direct or indirect relationship with the selection of a female in employment needs to be rigorously analyzed at broader level because the piece meal approach enhances the complications to understand the main hurdle that needs to be addressed to solve the long standing issue on the basis of justice, economic and ethical concerns. The researchers have to look the issue more comprehensively in larger settings to make a hierarchical study in the context of keeping a close focus on the basic line from where the gender discrimination may start, which ultimately becomes a mega problem at macro level, Therefore, a study has been proceeded to make a comprehensive study based on the government controlled sector of Peoples Republic of China and Pakistan, because both are different countries having entirely different setup at all levels.

\section{References}

Barber, A. E. (1998). Personnel recruitment research: Individual and organizational perspectives. Thousand Oaks, CA Sage.

Ben, C. Y., \& Broun, M. (2003). Crumbling ivory towers: Academic organizing and its gender effects. Gender, Work and Organization, 10(2), 194-212. http://dx.doi.org/10.1111/1468-0432.t01-1-00011

Bendyna, M. E., Finucane, T., Kirby, L., O’Donnell, J. P., \& Wilcox, C. (1996). Gender Differences in Public Attitudes toward the Gulf War: A Test of Competing Hypotheses. The Social Science Journal, 33, 1-22. http://dx.doi.org/10.1016/S0362-3319(96)90002-6

Broockman, D. E. (2012). Do Female Politicians Empower Women to Vote or Run for Office: A Regression Discontinuity Approach. Mimeograph, Department of Political Science University of California, Berkeley.

Broun's, M. (2000). The gendered nature of assessment procedures in scientific research funding: The Dutch case. Higher Education in Europe, 25, 193-201. http://dx.doi.org/10.1080/713669261

Carless, S. A. (2007). Graduate recruitment and selection in Australia. International Journal of Selection and Assessment, 15(2), 153-166. http://dx.doi.org/10.1111/j.1468-2389.2007.00377.x

Catano, V. M., Wiesner, W. H., Hackett, R. D., \& Methot, L. (2004). Recruitment and selection in Canada. Nelson Education Ltd.

Center for American Women and Politics (CAWP). (2010). Facts and Findings. Retrieved from http://www.cawp.rutgers.edu

Chi, W., \& Li, B. (2013). Trends in China's gender employment and pay gap: Estimating gender pay gaps with employment selection. Journal of Comparative Economics.

Cole, M., Field, H., \& Giles, W. (2004). Interaction of recruiter and applicant gender in resume evaluation: A field study. Sex Roles, 51(9/10), 597-608. http://dx.doi.org/10.1007/s11199-004-5469-1

Compton, R. L., Morrissey, W. J., Nankervis, A. R., \& Morrissey, B. (2009). Effective recruitment and selection practices. $\mathrm{CCH}$ Australia Limited.

Doherty, L., \& Manfredi, S. (2006). Women's progression to senior positions in English universities. Employee Relations, 28(6), 553-572. http://dx.doi.org/10.1108/01425450610704498

Dolan, K., (2006). Women candidates in American politics: What we know, what we want to know.Paper Presented at the 2006 Meeting of the Midwest Political Science Association.

Drory, A., \& Vigoda-Gadot, E. (2010). Organizational politics and human resource management: A typology and the Israeli experience. Human Resource Management Review, 20(3), 194-202. 
http://dx.doi.org/10.1016/j.hrmr.2009.08.005

Ely, R. J., \& Meyerson, D. E. (2000). Theories of gender in organizations: A new approach to organizational analysis and change. Research in Organizational Behavior, 22, 103-151. http://dx.doi.org/10.1016/S0191-3085(00)22004-2

Ferreira, F., \& Gyourko, J. (2014). Does gender matter for political leadership? The case of US mayors. Journal of Public Economics, 112, 24-39. http://dx.doi.org/10.1016/j.jpubeco.2014.01.006

Fogelberg, P., Hearn, J., Husu, L., \& Mankkinnen, T. (1999). Hard Work in the Academy. Helsinki: Helsinki University Press.

Gneezy, U., Leonard, K. L., \& List, J. A. (2008). Gender Differences in Competition: Evidence from a Matrilineal and a Patriarchal Society. Econometrica.

Górecki, M. A., \& Kukołowicz, P. (2014). Gender quotas, candidate background and the election of women: A paradox of gender quotas in open-list proportional representation systems. Electoral Studies, 36, 65-80. http://dx.doi.org/10.1016/j.electstud.2014.06.009

Harris, H. (2002). Think international manager, think male: Why are women not selected for international assignments? Thunderbird International Business Review, 44(2), 175-203.http://dx.doi.org/10.1002/tie.10010

Huang, J., \& Kisgen, D. (2013). Gender and corporate finance: Are male executives overconfident relative to female executive? J. Financ. Econ., 108, 822-839. http://dx.doi.org/10.1016/j.jfineco.2012.12.005

Huber, J. D., \& Nolan, M. (2004). Bureaucratic Capacity, Delegation, and Political Reform. American Political Science Review, 98(3), 481-94. http://dx.doi.org/10.1017/S0003055404001297

Huddy, L., \& Terkildsen, N. (1993). The consequences of gender stereotypes for women candidates at different levels and types of office. Polit. Res. Q., 46(3), 503-525. http://dx.doi.org/10.1177/106591299304600304

Husu, L. (2000). Gender discrimination in the promised land of gender equality. Higher Education in Europe, 25(2), 221-228. http://dx.doi.org/10.1080/713669257

Khurana, R. (2002). Searching for a Corporate Savior. The Irrational Quest for Charismatic CEO's. Princeton University Press, Princeton, NJ.

Krause, G. A., Lewis, D. E., \& Douglas, J. W. (2006). Political appointments, civil service systems, and bureaucratic competence: Organizational balancing and executive branch revenue forecasts in the American $\begin{array}{lllll}\text { states. American Journal of Political } & \text { Science, } & 50(3), & \text { 770-787. }\end{array}$ http://dx.doi.org/10.1111/j.1540-5907.2006.00215.x

Krymkowski, D. H., \& Mintz, B. (2008). What types of occupations are women entering? Determinants of changes in female representation: 1970-2000. Research in Social Stratification and Mobility, 26(1), 1-14. http://dx.doi.org/10.1016/j.rssm.2007.08.007

Kusterer. (2014). Gender equality and liberal individualism: Acritical reading of economist discourse in Sweden. Scandinavian Journal of Management, 30, 306-316. http://dx.doi.org/10.1016/j.scaman.2014.01.002

Lam, K. C., McGuinness, P. B., \& Vieito, J. P. (2013). CEO gender, executive compensation and firm performance in Chinese-listed enterprises. Pacific-Basin Finance Journal, 21(1), 1136-1159. http://dx.doi.org/10.1016/j.pacfin.2012.08.006

Levi, M., Li, K., \& Zhang, F. (2014). Director gender and mergers and acquisitions. Journal of Corporate Finance, 28, 185-200. http://dx.doi.org/10.1016/j.jcorpfin.2013.11.005

Lewis, P. (2003). New China-old ways? A case study of the prospects for implementing human resource management practices in a Chinese state-owned enterprise. Employee Relations, 25(1), 42-60. http://dx.doi.org/10.1108/01425450310453517

Linghag, S., \& Regnö, K. (2009). What is Gender in Organizations?

Liu, S. (2013). A few good women at the top: The China case. Business Horizons, 56(4), 483-490. http://dx.doi.org/10.1016/j.bushor.2013.04.002

Marshall, M. G., \& Ramsey, D. (1999). Gender empowerment and the willingness of states to use force. Unpublished research paper, Center for Systemic Peace. Retrieved from http://www.members.aol.com/CSPmgm 
McGuire, G. M. (2002). Gender, race, and the shadow structure a study of informal networks and inequality in a work organization. Gender \& Society, 16(3), 303-322. http://dx.doi.org/10.1177/0891243202016003003

Meyers-Levy, J., \& Loken, B. (2015). Revisiting gender differences: What we know and what lies ahead. Journal of Consumer Psychology, 25(1), 129-149. http://dx.doi.org/10.1016/j.jcps.2014.06.003

Moser, A. (2007). Gender and indicators: Overview report. Bridge: Institute of Development Studies.

Nabi, G., Wei, S., Husheng, X., Shabbir, M., Altaf, M., \& Zhao, S. (2014). Effective Recruitment and Selection Procedures: An Analytical Study Based on Public Sector Universities of Pakistan. Public Policy and Administration Research, 4(10), 12-20.

Nabi, G., Wei, S., Shabbir, M., \& Altaf, M. (2014). Procedural justice, organizational \& State Politics: The real challenge for the right selection in public sector institution of Pakistan. International Journal of Business Management and Research, 41(2), 1193-1201.

Nabi, G., Wei, S., Zhao, S., \& Shabbir, M. (2015). Selection Procedures, Face Validity and Fairness in Higher Academic Institutions of Pakistan. Journal of Management Research, 7(1). http://dx.doi.org/10.5296/jmr.v7i1.6964

Norris, P. (2006). The impact of electoral reform on women's representation. Actapolitica, 41(2), 197-213. http://dx.doi.org/10.1057/palgrave.ap.5500151

Ofori, D., \& Aryeetey, M. (2011). Recruitment and selection practices in small and medium enterprises: Perspectives from Ghana. International Journal of Business Administration, 2(3), 45-60. http://dx.doi.org/10.5430/ijba.v2n3p45

Phillips, A. (1995). The politics of presence. Oxford: Clarendon Press.

Rynes, S. L., \& Barber, A. E. (1990). Applicant Attraction Strategies: An organizational perspective. Academy of Management Review, 15, 286-310.http://dx.doi.org/10.2307/258158

Schnackenberg, A. K., \& Tomlinson, E. C. (2014). Organizational Transparency A New Perspective on Managing Trust in Organization-Stakeholder Relationships. Journal of Management. http://dx.doi.org/10.1177/0149206314525202

Schneider, B. R. (1992). Politics within the State: Elite bureaucrats and industrial policy in authoritarian Brazil. University of Pittsburgh Pre.

Schofield, T., \& Goodwin, S. (2005). Gender politics and public policy making: Prospects for advancing gender equality. Policy and Society, 24(4), 25-44. http://dx.doi.org/10.1016/S1449-4035(05)70067-9

Schueller-Weidekamm, C., \& Kautzky-Willer, A. (2012). Challenges of Work-Life Balance for Women Physicians/Mothers Working in Leadership Positions. Gender Medicine, 9(4), 244-250. http://dx.doi.org/10.1016/j.genm.2012.04.002

Steinpreis, R., Anders, K., \& Ritzke, D. (1999). The impact of gender on the review of the curricula vitae of job applicants and tenure applicants: A national empirical study. Sex Roles, 41(7/8), 509-528. http://dx.doi.org/10.1023/A:1018839203698

Syed, J., Özbilgin, M., Torunoglu, D., \& Ali, F. (2009). Rescuing gender equality from the false dichotomies of secularism versus shariah in Muslim majority countries. Women's Studies International Forum, 32(2), 67-79. http://dx.doi.org/10.1016/j.wsif.2009.03.007

Tate, G., \& Yang, L. (2014). Female leadership and gender equity: Evidence from plant closure. Journal of Financial Economics. http://dx.doi.org/10.1016/j.jfineco.2014.01.004i

Teigen, M. (2000). The amative action controversy. NORA, 2(8), 63-77.

Tigen, M. (2002). The suitable few: Managerial recruitment practices in the Norwegian state bureaucracy. Scandinavian Journal of Management, 18(2), 197-215. http://dx.doi.org/10.1016/S0956-5221(00)00029-4

Tong, J. (2003). The gender gap in political culture and participation in China. Communist and Post-Communist Studies, 36(2), 131-150. http://dx.doi.org/10.1016/S0967-067X(03)00022-9

Van Balen, B. (2001). Vrouwen in de Wetenschappelijke Arena.Socialesluiting in de universiteit (Women in the Academic Arena. Social Closure Inside the University), Het Spinhuis, Amsterdam.

Van den Brink, M., Brouns, M., \& Waslander, S. (2006). Does excellence have a gender? A national research study on recruitment and selection procedures for professorial appointments in The Netherlands. Employee 
Relations, 28(6), 523-539. http://dx.doi.org/10.1108/01425450610704470

Van, M., \& Ben, Y. (2012). Gender practices in the construction of academic excellence: Sheep with five legs. Organization, 19(4), 507-524. http://dx.doi.org/10.1177/1350508411414293

Van, M., Ben, Y., \& Jansen, W. (2010). Transparency in academic recruitment: A problematic tool for gender equality? Organization Studies, 31(11), 1459-1483. http://dx.doi.org/10.1177/0170840610380812

Vigoda, E. (2000). Organizational politics, job attitudes, and work outcomes: Exploration and implications for the public sector. Journal of vocational Behavior, 57(3), 326-347. http://dx.doi.org/10.1006/jvbe.1999.1742

Ziegler, B. (2001). Some remarks on gender equality in higher education in Switzerland. International Journal of Sociology and Social Policy, 21(1-2), 44-49. http://dx.doi.org/10.1108/01443330110789556

\section{Copyrights}

Copyright for this article is retained by the author(s), with first publication rights granted to the journal.

This is an open-access article distributed under the terms and conditions of the Creative Commons Attribution license (http://creativecommons.org/licenses/by/3.0/). 